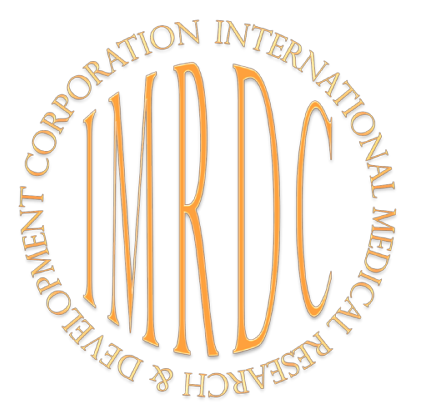

\title{
Mechanisms for Cardiac Troponin Increase in Arterial Hypertension
}

\author{
Aleksey M. Chaulin ${ }^{1,2}$ \\ 'Samara State Medical University \\ ${ }^{2}$ Samara Regional Clinical Cardiology Dispensary \\ Samara, the Russian Federation
}

\begin{abstract}
Despite the fact that cardiac troponins (cTnI and cTnT) are cardiospecific, they can be elevated in many systemic and noncardiac physiological and pathological conditions. The diagnostic value of cTnI and cTnT significantly depends on the method of their determination. Thus, previously used low- and moderate-sensitivity immunoassays detected only serious myocardial damage and did not determine troponins in patients suffering from certain chronic pathologies. High-sensitivity troponin assays can detect minor damage to cardiac muscle cells in many pathological conditions, and troponin levels have a high predictive value. Among the early pathological conditions requiring the attention of clinicians is arterial hypertension (AH), which is also accompanied by an increase in the levels of hsTn in serum and urine. Currently, mechanisms responsible for increased levels of cardiac troponins in the blood serum and urine in hypertension are not well covered in the scientific literature. This article discusses in detail the presumptive mechanisms that cause increased levels of cTnI and cTnT in AH.(International Journal of Biomedicine. 2021;11(4):397-402.)
\end{abstract}

Key Words: cardiac troponins $\bullet$ cardiovascular disease $\bullet$ arterial hypertension $\bullet$ glomerular filtration rate

For citation: Chaulin AM. Mechanisms for Cardiac Troponin Increase in Arterial Hypertension. International Journal of Biomedicine. 2021;11(4):397-402. doi:10.21103/Article11(4)_RA2

\section{Abbreviations}

AH, arterial hypertension; AMI, acute myocardial infarction; CVD, cardiovascular disease; cTnT, cardiac troponin T; cTnI, cardiac troponin I; GFR, glomerular filtration rate; hsTn, high-sensitivity troponin; MMP2, matrix metalloproteinase-2; Tn, troponin; TnT, troponin $\mathrm{T}$.

$\mathrm{T}$ The cardiac troponin (cTn) complex is a critical regulator of cardiac muscle contraction. $\mathrm{cTn}$ is composed of three distinct subunits named according to their functions: a highly conserved $\mathrm{Ca}^{2+}$ binding subunit $(\mathrm{cTnC})$; an actomyosin ATPase inhibitory subunit (cTnI), and a tropomyosin binding subunit $(\mathrm{cTnT}) .^{(1,2)}$ The importance of $\mathrm{cTn}$ in the regulation of myocardial function is evidenced by the fact that mutations causing changes in the amino acid sequence in cTnI, cTnT, cTnC are accompanied by significant and lifethreatening disorders of the contractile function of the cardiac

*Corresponding author: Aleksey M. Chaulin, PGS. Samara State Medical University. Samara, the Russian Federation. E-mail: alekseymichailovich22976@gmail.com muscle, and in particular, hereditary cardiomyopathies. ${ }^{(3-5)}$ The amino acid composition of $\mathrm{cTnC}$ is similar to the amino acid composition of $\mathrm{TnC}$ in skeletal muscle fibers; therefore, this protein is not used as a biomarker of AMI. On the contrary, the amino acid composition of $\mathrm{cTnI}$ and $\mathrm{cTnT}$ is unique, giving them the necessary specificity, which is very important for use in AMI diagnosis ${ }^{\left({ }^{(6-8)}\right.}$ In addition to the specific structure of the protein, the features of determination methods play an important role in laboratory diagnostics, which are constantly being improved and change our understanding of the biology and diagnostic value of many biomarkers, including $\mathrm{cTnI}$ and cTnT. ${ }^{(6-10)}$ For example, the methods for determining cTnI and cTnT, originally developed by Cummins and Katus, ${ }^{(1-13)}$ were characterized by low sensitivity and specificity, which was manifested by the relatively late detection of diagnostically 
significant concentrations in AMI patients and a significant number of nonspecific (cross) reactions of anti-cTnI and anti$\mathrm{cTnT}$ antibodies with troponins released from damaged skeletal muscle fibers during rhabdomyolysis and/or exercise. ${ }^{(14-16)}$

The use of hs-cTn assays showed that the levels of $\mathrm{cTnI}$ and cTnT depend on a number of biological factors, including gender, age, and circadian characteristics. ${ }^{(17-20)}$ The gender peculiarities of the levels of cTnI and cTnT are that the serum levels of the latter are significantly higher in men than in women, which is typical for almost all high-sensitivity immunoassays currently used. By analogy with another cardiac-specific enzyme (creatine kinase) and creatinine, a product of protein metabolism, the gender differences in troponin concentrations are due to a higher mass of striated muscles, including cardiac muscles, in males. ${ }^{(6,17)}$ Age-related features of the levels of cTnI and cTnT are characterized by higher levels of troponins in elderly patients than in young patients and, most likely, are associated with the presence of chronic latent comorbid pathologies that cause subclinical lesions of cardiomyocytes. ${ }^{(6,21-23)}$ Circadian features consist in the predominance of morning levels of troponins over evening ones, which is explained by the increased activity of a number of systems of the human body. The increased activity of these systems is an evolutionarily developed adaptive mechanism necessary for a healthy person for the period of wakefulness ${ }^{(24)}$ however, these systems also have a negative effect on myocardial cells. ${ }^{(25)}$ It should be noted that a number of studies using high-sensitivity immunoassays have shown that cTnI and cTnT can be determined not only in blood serum, but also in urine and saliva, ${ }^{(26-31)}$ and the levels of cTnI and cTnT significantly differ between the patient groups and healthy individuals. In the future, the indicated scientific data will allow the development of new diagnostic approaches. In particular, the idea of creating test strips to determine cTnI and $\mathrm{cTnT}$ in non-invasively obtained biological fluids has been proposed. ${ }^{(32)}$
High-sensitivity methods for determining cTnI and cTnT have demonstrated that cardiomyocytes are extremely sensitive to any kind of damage, and the concentration of $\mathrm{cTnI}$ and $\mathrm{cTnT}$ can increase in many pathological and physiological conditions (Table 1). Moreover, even in healthy patients, cTnI and cTnT are released from cardiomyocytes, but their concentration, as a rule, does not exceed the 99th percentile. ${ }^{(9)}$ The mechanisms underlying the $\mathrm{cTnI}$ and $\mathrm{cTnT}$ release from cardiomyocytes and, accordingly, their increase in serum in healthy patients, have not been conclusively established.

Currently, there are a considerable number of review articles that discuss in detail the mechanisms for increasing cTnI and cTnT in many cardiac (myocarditis, cardiomyopathy, heart failure, arrhythmias) $)^{(32-35)}$ and noncardiac pathologies; (sepsis, exercise, renal failure, cancer, the use of chemotherapeutic drugs) ${ }^{(46-39)}$ however, $\mathrm{AH}$ is rarely discussed in this respect. The purpose of this article was to review some hypothetical mechanisms for increasing cTnI and cTnT in human biological fluids.

\section{Mechanisms responsible for increased levels of $\mathrm{cTnI}$ and $\mathrm{cTnT}$ in $\mathrm{AH}$}

Although the molecules of cardiac troponins, taking into account their molecular weight (cTnI-25 kDa, cTnT-37 $\mathrm{kDa}$ ), are low-molecular-weight proteins; whole molecules cannot pass through the intact membrane of cardiomyocytes. However, like any protein molecules, cTnT and cTnI are extremely sensitive to the action of proteases, which can be activated under certain pathological conditions. According to the results of experimental studies, stretching of the cardiac muscle tissue, oxidative stress, and ischemia of cardiomyocytes lead to the activation of MMP2, which, in turn, cleaves the cTnI molecule into small peptide fragments that can pass through the cardiomyocyte membrane into the extracellular space and, further, into the blood. ${ }^{(40-42)}$ Another intracellular enzyme that can cause the degradation of $\mathrm{cTnI}$ is calpain-1, whose activity

Table 1.

Pathological and physiological conditions causing an increase in the levels of cardiac troponins in addition to AMI, according to $[8,19]$ with changes and additions

\begin{tabular}{|c|c|c|}
\hline \multicolumn{3}{|c|}{ The possible causes of elevated serum cTns in addition to AMI } \\
\hline Myocardial damage in cardiac pathologies & $\begin{array}{c}\text { Myocardial damage in non-cardiac and } \\
\text { systemic pathological and physiological } \\
\text { conditions }\end{array}$ & False positive cTn elevation \\
\hline $\begin{array}{l}\text { - Inflammatory heart diseases (endocarditis, } \\
\text { myocarditis, pericarditis) } \\
\text { - Cardiac arrhythmias (atrial fibrillation, } \\
\text { supraventricular tachycardia and others) } \\
\text { - Cardiomyopathies (all types) and heart failure } \\
\text { - Cardiotoxic drugs (chemotherapeutic drugs for } \\
\text { the treatment of cancer, adrenomimetics, cocaine, } \\
\text { and others) } \\
\text { - Cardiac surgery (CABG, catheter ablation, } \\
\text { and others) }\end{array}$ & $\begin{array}{l}\text { - Physiological conditions (heavy physical } \\
\text { exertion, stressful situations, old age, male } \\
\text { gender, morning time interval) } \\
\text { - Sepsis } \\
\text { - Chronic diseases (chronic renal failure, } \\
\text { chronic obstructive pulmonary disease, } \\
\text { diabetes mellitus, oncological diseases) } \\
\text { - Pulmonary embolism } \\
\text { - Disorders of the central nervous system } \\
\text { stroke, subarachnoid hemorrhage) } \\
\text { - COVID-19 }\end{array}$ & $\begin{array}{l}\text { - Heterophilic antibodies } \\
\text { - Rheumatoid factor } \\
\text { - Biotin } \\
\text { - Hemolysis } \\
\text { - Fibrin clots in the blood serum } \\
\text { - Cross (nonspecific) reactions of } \\
\text { diagnostic antibodies with skeletal } \\
\text { muscle troponin isoforms }\end{array}$ \\
\hline
\end{tabular}


increases with increasing load on the myocardium under experimental conditions. ${ }^{(43)}$ Blocking calpain-1 with a specific inhibitor reduces the degradation of the troponin molecule. (44) Since under conditions of AH the load on the myocardium increases significantly, the fragmentation of troponins and the release of the smaller fragments from cardiomyocytes can be considered very reasonable.

In addition to proteolytic cleavage of troponins, the activated proteases are likely to induce proteolysis and cleavage of protein components of the cardiomyocyte membrane, facilitating the release of cytoplasmic proteins. In cardiomyocytes, approximately $5 \%$ of the total troponins are located outside the troponin complex directly in the cytoplasm (cytoplasmic or non-structural fraction). It is believed that the troponin proteins that make up this fraction are released first in pathological and physiological conditions. At the same time, given the relatively small volume of this fraction, the troponin levels in reversible myocardial damage, for example, during heavy physical exertion or stressful situations, do not exceed the 99th percentile by more than 3-5 times. ${ }^{(45-47)}$ Considering the small degree of an increase in cardiac troponins in $\mathrm{AH}$, it can be assumed that the key contributor to the increase is also made by the cytoplasmic fraction of troponins. ${ }^{(48-50)}$

Along with the intracellular proteolytic cleavage of troponins, the membrane permeability of cardiomyocytes also plays an important role, which can change under a number of physiological and pathological conditions. According to Hessel et al., myocardial overload leads to stretching of the heart muscle and activation of transmembrane glycoprotein receptors called integrins. These proteins function as mechanotransducers, increasing membrane permeability, and activating MMP-2 and calpain-1, which additionally enhance proteolytic degradation of troponins. ${ }^{(51)}$ Thus, the cleavage of troponins into small fragments and an increase in the permeability of the cardiomyocyte membrane create the necessary conditions for the release of the cytoplasmic pool of troponins, which leads to increasing the levels of cardiac troponins in $\mathrm{AH}$.

\section{Apoptosis of cardiomyocytes}

Apoptosis of cardiomyocytes is initiated by a number of mechanisms that may be associated with the development and progression of AH. According to the results of a study by Cheng et al., ${ }^{(52)}$ stretching the heart muscle increases oxidative stress and the expression of the Fas protein, which is one of the key inducers for programmed cell death. Another mechanism causing increased apoptosis of cardiomyocytes is the action of the adrenergic system, an increase in the activity of which is very characteristic for AH. Experimental studies have shown that the effect of beta-adrenergic receptor agonists (norepinephrine and isoproterenol) on cardiomyocytes is that they trigger intracellular apoptotic signals by cAMP-dependent and NF2-dependent mechanisms. ${ }^{(53-55)}$ Programmed death of cardiomyocytes can lead to very significant increases in cTn levels, as demonstrated in a recent experimental study by Weil et al. ${ }^{(56)}$ In that experiment, the researchers initiated apoptosis in the porcine myocardium by short-term overloading of the left ventricle with pressure. At the same time, after 30 minutes the levels of troponins already exceeded the upper limit of the norm, and after 1 and 24 hours the concentrations of TnT reached relatively high values $(856 \pm 956 \mathrm{ng} / 1$ and $1.462 \pm 1.691$ $\mathrm{ng} / \mathrm{l}$, respectively). At the same time, the researchers did not reveal any histological signs of cardiomyocyte necrosis, which indicates that the mechanism for apoptosis of myocardial cells was responsible for the increase in serum troponin levels. ${ }^{(56)}$

\section{Features of cTn elimination through the glomerular filter: Influencing factors and possibilities of non-invasive diagnostics}

In addition to the mechanisms for the release of troponin into the systemic circulation following myocardial cell injury, the mechanisms for troponin elimination from blood play an important role. Thus, in patients with no signs of CVD, but with signs of chronic renal failure, elevated troponin levels are often observed. ${ }^{(57,58)}$ Moreover, in patients with a lower GFR, troponin levels are higher than in patients with a higher GFR. ${ }^{(58)}$ However, direct evidence for the elimination of troponins through the glomerular filter, in particular studies confirming the presence of troponins in urine, has been lacking for a long time. In some studies, urinary troponin levels were detected only in isolated cases, and therefore this mechanism for troponin elimination was considered questionable. ${ }^{(59)}$ Troponin molecules were considered relatively large and, according to some authors, could not pass through the glomerular filter. ${ }^{(59)}$ However, several recent studies have shown the presence of troponin molecules in urine in patients with CVD. For example, in a study by Pervan et al., ${ }^{(26)} \mathrm{hsTnI}$ was found in morning urine in patients with $\mathrm{AH}$ and normotensive individuals. However, in hypertensive patients, the mean hsTnI value was higher than in those with normal blood pressure. Since AH enhances GFR, it is probably this mechanism that determines the results obtained. Levels of troponins in urine are relatively low, which explains why moderate-sensitivity assays did not detect these concentrations. It should be noted that in the study by Pervan et al., ${ }^{(26)}$ a high-sensitivity troponin assay was used to determine hsTnI in urine. In a study by Chen et al., ${ }^{(27)}$ the authors observed significantly higher levels of urine hsTnI in patients with diabetes mellitus than in those without subsequent incident cardiovascular events. The multivariate logistic regression analysis using different models consistently showed that urine hsTnI $>4.10 \mathrm{pg} / \mathrm{mL}$ was an independent factor predictive of incident cardiovascular events.

A possible explanation for how troponin molecules penetrate theglomerularfilteris the proteolytic cleavageprocesses under the influence of a number of intra- and extracellular proteinases, most likely, splitting into small fragments that can penetrate into urine and saliva. ${ }^{(26-28,60)}$ However, the processes of proteolytic cleavage of troponins inside cells and in blood serum are extremely poorly understood. Although researchers report several dozen fragments of various molecular weights and sizes, all the enzymes that are responsible for the cleavage of troponins and the formation of such a significant number of fragments are unknown. ${ }^{(61-63)}$ At the same time, the results of the study by Katrukha et al. ${ }^{(61)}$ suggest that the 29-kDa fragment of cTnT in AMI serum samples mainly appears due to the cleavage by thrombin during serum sample preparation. It is noteworthy 
that under conditions of hypertension, thrombin is activated, ${ }^{(64)}$ and, accordingly, the processes of proteolytic cleavage of troponins into small fragments are enhanced, and an increase in GFR promotes the elimination of formed small fragments through the glomerular filter into the urine. The identification of all factors influencing the proteolytic degradation of troponin molecules is essential for understanding this process and improving laboratory diagnostics, including the use of urine as a non-invasive biomaterial. The mechanisms described above for increasing the levels of cTnT and $\mathrm{cTnI}$ in human biological fluids in $\mathrm{AH}$ are summarized in Figure 1.

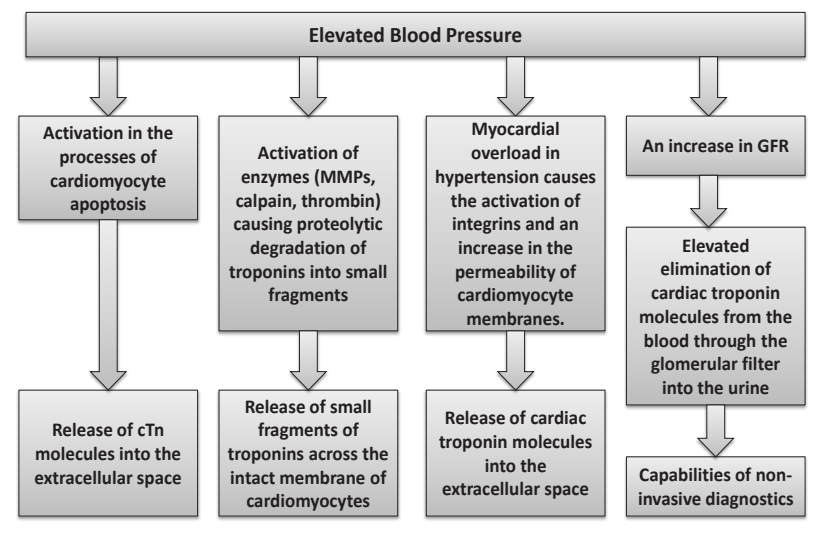

Fig. 1. Mechanisms responsible for increased levels of cardiac troponins in $A H$.

In conclusion, the increase in the levels of cardiac troponins in $\mathrm{AH}$ is based on the following mechanisms: activation of proteolytic cleavage of troponin molecules inside cardiomyocytes, the increased permeability of cardiomyocyte membranes, and the increased apoptotic processes, as well as the effect of $\mathrm{AH}$ on the filtration of troponin fragments through the glomerular filter into the urine. Measurement of urinary hsTn, collected easily and non-invasively, can be an acceptable biomarker with a high diagnostic value.

\section{References}

1. Gomes AV, Potter JD, Szczesna-Cordary D. The role of troponins in muscle contraction. IUBMB Life. 2002 Dec;54(6):323-33. doi: 10.1080/15216540216037. PMID: 12665242 .

2. Gordon AM, Homsher E, Regnier M. Regulation of contraction in striated muscle. Physiol Rev. 2000 Apr;80(2):853-924. doi: 10.1152/physrev.2000.80.2.853.

3. Clippinger SR, Cloonan PE, Wang W, Greenberg L, Stump WT, Angsutararux P, Nerbonne JM, Greenberg MJ. Mechanical dysfunction of the sarcomere induced by a pathogenic mutation in troponin $\mathrm{T}$ drives cellular adaptation. J Gen Physiol. 2021 May 3;153(5):e202012787. doi: 10.1085/ jgp.202012787.

4. Na I, Kong MJ, Straight S, Pinto JR, Uversky VN. Troponins, intrinsic disorder, and cardiomyopathy. Biol Chem. 2016;397(8):731-751. doi:10.1515/hsz-2015-0303.

5. Duplyakov DV, Chaulin AM. Mutations of heart troponines, associated with cardiomyopathies. Kardiologiya: Novosti, Mneniya, Obuchenie [Cardiology: News, Opinions, Training]. 2019;7(3):8-17. doi: 10.24411/2309-1908-201913001. [Article in Russian].

6. Chaulin AM, Abashina OE, Duplyakov DV. [Highsensitivity cardiac troponins: detection and central analytical characteristics]. Cardiovascular Therapy and Prevention. 2021;20(2):2590. doi:10.15829/1728-8800-2021-2590. [Article in Russian].

7. Chaulin AM, Grigorieva YuV, Pavlova TV, Duplyakov DV. [Diagnostic significance of complete blood count in cardiovascular patients; Samara State Medical University]. Russian Journal of Cardiology. 2020;25(12):3923. doi: 10.15829/1560-4071-2020-3923. [Article in Russian]. 8. Chaulin AM, Duplyakov DV. Increased cardiac troponins, not associated with acute coronary syndrome. Part 1. Kardiologiya: Novosti, Mneniya, Obuchenie [Cardiology: News, Opinions, Training]. 2019;7(2):13-23. doi: 10.24411/2309-1908-2019-12002. [Article in Russian].

9. Chaulin AM, Karslyan LS, Bazyuk EV, Nurbaltaeva DA, Duplyakov DV. [Clinical and Diagnostic Value of Cardiac Markers in Human Biological Fluids]. Kardiologiia. 2019. Dec11;59(11):66-75. doi: 10.18087/cardio.2019.11.n414. [Article in Russian].

10. Chaulin AM, Karslyan LS, Grigorieva EV, Nurbaltaeva DA, Duplyakov DV. Metabolism of cardiac troponins (Literature review). Complex Issues of Cardiovascular Diseases. 2019;8(4):103-115. doi: 10.17802/2306-1278-20198-4-103-115. [Article in Russian].

11. Cummins B, Auckland ML, Cummins P. Cardiac-specific troponin-I radioimmunoassay in the diagnosis of acute myocardial infarction. Am Heart J. 1987 Jun;113(6):1333-44. doi: 10.1016/0002-8703(87)90645-4.

12. Katus HA, Looser S, Hallermayer K, Remppis A, Scheffold T, Borgya A, Essig U, Geuss U. Development and in vitro characterization of a new immunoassay of cardiac troponin T. Clin Chem. 1992 Mar;38(3):386-93.

13. Collinson PO, Boa FG, Gaze DC. Measurement of cardiac troponins. Ann Clin Biochem. $2001 \mathrm{Sep} ; 38(\mathrm{Pt} 5)$ :423-49. doi: 10.1177/000456320103800501. PMID: 11587122.

14. Hossein-Nia M, Nisbet J, Merton GK, Holt DW. Spurious rises of cardiac troponin T. Lancet. 1995;346(8989):1558. doi:10.1016/s0140-6736(95)92087-0.

15. Löfberg $M$, Tähtelä R, Härkönen $M$, Somer H. Cardiac troponins in severe rhabdomyolysis. Clin Chem. 1996 Jul;42(7):1120-1. PMID: 8674206.

16. Benoist JF, Cosson C, Mimoz O, Edouard A. Serum cardiac troponin I, creatine kinase (CK), and CK-MB in early posttraumatic rhabdomyolysis. Clin Chem. 1997 Feb;43(2):416-7. PMID: 9023157.

17. Mueller-Hennessen M, Giannitsis E. Do we need to consider age and gender for accurate diagnosis of myocardial infarction? Diagnosis (Berl). 2016 Dec 1;3(4):175-181. doi: 10.1515/dx-2016-0023.

18. Yang S, Huai W, Qiao R, Cui L, Liu G, Wu J, Li A, Zhang J. Age and Gender Tailored Cutoff Value of hs-cTnT Contributes to Rapidly Diagnose Acute Myocardial Infarction in Chest Pain Patients. Clin Lab. 2016 Aug 1;62(8):14511459. doi: 10.7754/Clin.Lab.2016.151201.

19. Chaulin AM, Duplyakov DV. [High-sensitivity cardiac troponins: circadian rhythms]. Cardiovascular Therapy and Prevention. 2021;20(1):82-88. doi:10.15829/1728-88002021-2639. [Article in Russian]. 
20. Chaulin AM, Duplyakova PD, Duplyakov DV. [Circadian rhythms of cardiac troponins: mechanisms and clinical significance]. Russian Journal of Cardiology. 2020;25:4061. doi: 10.15829/1560-4071-2020-4061.[Article in Russian].

21. Chaulin AM, Duplyakov DV. [Increased natriuretic peptides, not associated with heart failure]. Russian Journal of Cardiology. 2020;:4140. doi: 10.15829/1560-4071-20204140. [Article in Russian].

22. Chaulin AM, Duplyakov DV. Comorbidity in chronic obstructive pulmonary disease and cardiovascular disease. Cardiovascular Therapy and Prevention. 2021;20(3):2539. doi; 10.15829/1728-8800-2021-2539. [Article in Russian].

23. Chaulin AM, Svechkov NA, Volkova SL, Grigoreva YuV. Diagnostic value of cardiac troponins in elderly patients without myocardial infarction. Modern problems of science and education. 2020;6. doi: 10.17513/spno.30302. [Article in Russian].

24. Chaulin AM, Duplyakov DV. Environmental factors and cardiovascular diseases. Hygiene and Sanitation. 2021;100(3):223-228. doi: 10.47470/0016-9900-2021-100-3223-228. [Article in Russian].

25. Chaulin AM, Duplyakov VD. On the potential effect of circadian rhythms of cardiac troponins on the diagnosis of acute myocardial infarction. Signa Vitae. 2021.doi:10.22514/ sv.2021.050.

26. Pervan P, Svaguša T, Prkačin I, Savuk A, Bakos M, Perkov S. Urine high sensitive Troponin I measuring in patients with hypertension. Signa Vitae. 2017;13:62-64. doi: 10.22514/ SV133.062017.13.

27. Chen JY, Lee SY, Li YH, Lin CY, Shieh MD, Ciou DS. Urine High-Sensitivity Troponin I Predict Incident Cardiovascular Events in Patients with Diabetes Mellitus. J Clin Med. 2020 Dec 2;9(12):3917. doi: 10.3390/jcm9123917. 28. Potkonjak AM, Sabolović Rudman S, Nikolac Gabaj N, Kuna K, Košec V, Stanec Z, Zovak M, Tučkar N, Djaković I, Prkačin I, Svaguša T, Bakoš M. Urinary troponin concentration as a marker of cardiac damage in pregnancies complicated with preeclampsia. Med Hypotheses. 2020 Nov; 144:110252. doi: 10.1016/j.mehy.2020.110252.

29. Chaulin AM, Duplyakova PD, Bikbaeva GR, et al. [Concentration of high-sensitivity cardiac troponin I in the oral fluid in patients with acute myocardial infarction: a pilot study]. Russian Journal of Cardiology. 2020;25(12):3814. doi: 10.15829/1560-4071-2020-3814. [Article in Russian].

30. Mirzaii-Dizgah I, Riahi E. Salivary high-sensitivity cardiac troponin T levels in patients with acute myocardial infarction. Oral Diseases. 2013;19(2):180-4. doi: 10.1111/j.16010825.2012.01968.x.

31. Chaulin A. Cardiac Troponins: Contemporary Biological Data and New Methods of Determination. Vasc Health Risk Manag. 2021;17:299-316. doi: 10.2147/VHRM.S300002.

32. Piccioni A, Brigida M, Loria V, Zanza C, Longhitano Y, Zaccaria R, Racco S, Gasbarrini A, Ojetti V, Franceschi F, Candelli M. Role of troponin in COVID-19 pandemic: a review of literature. Eur Rev Med Pharmacol Sci. 2020 Oct;24(19):1029310300. doi: 10.26355/eurrev_202010 23254.

33. Kruska M, El-Battrawy I, Behne-s M, Borggrefe M, Akin I. Biomarkers in Cardiomyopathies and Prediction of Sudden Cardiac Death. Curr Pharm Biotechnol. 2017;18(6):472-481. doi:10.2174/1389201018666170623125842

34. Chaulin AM, Duplyakov DV. MicroRNAs in Atrial Fibrillation: Pathophysiological Aspects and Potential Biomarkers. International Journal of Biomedicine.
2020;10(3):198-205. doi: 10.21103/Article10(3) RA3. 35. Bessière F, Khenifer S, Dubourg J, Durieu I, Lega JC. Prognostic value of troponins in sepsis: a meta-analysis. Intensive Care Med. 2013;39(7):1181-1189. doi:10.1007/ s00134-013-2902-3.

36. Aakre KM, Omland T. Physical activity, exercise and cardiac troponins: Clinical implications. Prog Cardiovasc Dis. 2019;62(2):108-115. doi:10.1016/j.pcad.2019.02.005.

37. Han X, Zhang S, Chen Z, Adhikari BK, Zhang Y, Zhang J, Sun J, Wang Y. Cardiac biomarkers of heart failure in chronic kidney disease. Clin Chim Acta. 2020 Nov;510:298-310. doi: 10.1016/j.cca.2020.07.040.

38. Chaulin AM, Duplyakov DV. Arrhythmogenic effects of doxorubicin. Complex Issues of Cardiovascular Diseases. 2020;9(3):69-80. doi: 10.17802/2306-1278-2020-9-3-69-80.

39. Chaulin AM, Abashina OE, Duplyakov DV. Pathophysiological mechanisms of cardiotoxicity in chemotherapeutic agents. Russian Open Medical Journal 2020; 9: e0305. doi: 10.15275/rusomj.2020.0305.

40. Kandasamy AD, Chow AK, Ali MA, Schulz R. Matrix metalloproteinase-2 and myocardial oxidative stress injury: beyond the matrix. Cardiovasc Res. 2010 Feb 1;85(3):413-23. doi: $10.1093 / \mathrm{cvr} / \mathrm{cvp} 268$.

41. Hughes BG, Schulz R. Targeting MMP-2 to treat ischemic heart injury. Basic Res Cardiol. 2014;109(4):424. doi:10.1007/ s00395-014-0424-y

42. Wang W, Schulze CJ, Suarez-Pinzon WL, Dyck JR, Sawicki $\mathrm{G}$, Schulz R. Intracellular action of matrix metalloproteinase-2 accounts for acute myocardial ischemia and reperfusion injury. Circulation. 2002 Sep 17;106(12):1543-9. doi: 10.1161/01. cir.0000028818.33488.7b.

43. Feng J, Schaus BJ, Fallavollita JA, Lee TC, Canty JM Jr. Preload induces troponin I degradation independently of myocardial ischemia. Circulation. 2001 Apr 24;103(16):20357. doi: 10.1161/01.cir.103.16.2035.

44. Maekawa A, Lee JK, Nagaya T, Kamiya K, Yasui K, Horiba M, Miwa K, Uzzaman M, Maki M, Ueda Y, Kodama I. Overexpression of calpastatin by gene transfer prevents troponin I degradation and ameliorates contractile dysfunction in rat hearts subjected to ischemia/reperfusion. J Mol Cell Cardiol. 2003 Oct;35(10):1277-84. doi: 10.1016/s00222828(03)00238-4.

45. Richardson AJ, Leckie T, Watkins ER, Fitzpatrick D, Galloway R, Grimaldi R, Baker P. Post marathon cardiac troponin $\mathrm{T}$ is associated with relative exercise intensity. $\mathrm{J}$ Sci Med Sport. 2018 Sep;21(9):880-884. doi: 10.1016/j. jsams.2018.02.005.

46. Martínez-Navarro I, Sánchez-Gómez J, Sanmiguel D, Collado E, Hernando B, Panizo N, Hernando C. Immediate and 24-h post-marathon cardiac troponin $\mathrm{T}$ is associated with relative exercise intensity. Eur J Appl Physiol. 2020 Aug;120(8):1723-1731. doi: 10.1007/s00421-020-04403-8. 47. Lazzarino AI, Hamer M, Gaze D, Collinson P, Steptoe A. The association between cortisol response to mental stress and high-sensitivity cardiac troponin $\mathrm{T}$ plasma concentration in healthy adults. J Am Coll Cardiol. 2013 Oct 29;62(18):16941701. doi: 10.1016/j.jacc.2013.05.070.

48. Afonso L, Bandaru H, Rathod A, Badheka A, Ali Kizilbash M, Zmily H, et al. Prevalence, determinants, and clinical significance of cardiac troponin-I elevation in individuals admitted for a hypertensive emergency. J Clin Hypertens (Greenwich). 2011 Aug;13(8):551-6. doi: 10.1111/j.17517176.2011.00476.x. 
49. Papadopoulos DP, Sanidas EA, Viniou NA, Gennimata V, Chantziara V, Barbetseas I, Makris TK. Cardiovascular hypertensive emergencies. Curr Hypertens Rep. 2015 Feb;17(2):5. doi: 10.1007/s11906-014-0515-z.

50. Pattanshetty DJ, Bhat PK, Aneja A, Pillai DP. Elevated troponin predicts long-term adverse cardiovascular outcomes in hypertensive crisis: a retrospective study. J Hypertens. 2012 Dec;30(12):2410-5. doi: 10.1097/HJH.0b013e3283599b4f.

51. Hessel MH, Atsma DE, van der Valk EJ, Bax WH, Schalij MJ, van der Laarse A. Release of cardiac troponin I from viable cardiomyocytes is mediated by integrin stimulation. Pflugers Arch. 2008 Mar;455(6):979-86. doi: 10.1007/s00424-0070354-8.

52. Cheng W, Li B, Kajstura J, Li P, Wolin MS, Sonnenblick EH, Hintze TH, et al. Stretch-induced programmed myocyte cell death. J Clin Invest. 1995 Nov;96(5):2247-59. doi: 10.1172/JCI118280

53. Singh K, Communal C, Sawyer DB, Colucci WS. Adrenergic regulation of myocardial apoptosis. Cardiovasc Res. 2000 Feb;45(3):713-9. doi: 10.1016/s00086363(99)00370-3.

54. Singh K, Xiao L, Remondino A, Sawyer DB, Colucci WS. Adrenergic regulation of cardiac myocyte apoptosis. J Cell Physiol. 2001 Dec;189(3):257-65. doi: 10.1002/jcp.10024.

55. Dalal S, Connelly B, Singh M, Singh K. NF2 signaling pathway plays a pro-apoptotic role in $\beta$-adrenergic receptor stimulated cardiac myocyte apoptosis. PLoS One. 2018 Apr 30;13(4):e0196626. doi: 10.1371/journal.pone.0196626.

56. Weil BR, Suzuki G, Young RF, Iyer V, Canty JM Jr. Troponin Release and Reversible Left Ventricular Dysfunction After Transient Pressure Overload. J Am Coll Cardiol. 2018 Jun 26;71(25):2906-2916. doi: 10.1016/j. jacc.2018.04.029.

57. Stacy SR, Suarez-Cuervo C, Berger Z, et al. Role of troponin in patients with chronic kidney disease and suspected acute coronary syndrome: a systematic review. Ann Intern Med. 2014;161(7):502-512. doi:10.7326/M14-0746

58. Dubin RF, Li Y, He J, Jaar BG, Kallem R, Lash JP, Makos G, et al; CRIC Study Investigators. Predictors of high sensitivity cardiac troponin $\mathrm{T}$ in chronic kidney disease patients: a cross-sectional study in the chronic renal insufficiency cohort (CRIC). BMC Nephrol. 2013 Oct 22;14:229. doi: 10.1186/1471-2369-14-229.

59. Ziebig R, Lun A, Hocher B, Priem F, Altermann C, Asmus $\mathrm{G}$, Kern H, et al. Renal elimination of troponin $\mathrm{T}$ and troponin I. Clin Chem. 2003 Jul;49(7):1191-3. doi: 10.1373/49.7.1191. 60. Chaulin AM, Duplyakova PD, Bikbaeva GR, Tukhbatova AA, Grigorieva EV, Duplyakov DV. [Concentration of highsensitivity cardiac troponin I in the oral fluid in patients with acute myocardial infarction: a pilot study]. Russian Journal of Cardiology. 2020;25(12):3814. doi: 10.15829/1560-40712020-3814. [Article in Russian].

61. Katrukha IA, Kogan AE, Vylegzhanina AV, Serebryakova MV, Koshkina EV, Bereznikova AV, Katrukha AG. ThrombinMediated Degradation of Human Cardiac Troponin T. Clin Chem. 2017 Jun;63(6):1094-1100. doi: 10.1373/ clinchem.2016.266635.

62. Chaulin AM. Phosphorylation and Fragmentation of the Cardiac Troponin T: Mechanisms, Role in Pathophysiology and Laboratory Diagnosis. International Journal of Biomedicine. 2021;11(3):250-259.DOI: 10.21103/Article11(3) RA2

63. Chaulin AM. Cardiac Troponins Metabolism: From Biochemical Mechanisms to Clinical Practice (Literature Review). Int J Mol Sci. 2021 Oct 10;22(20):10928. doi: 10.3390/ijms222010928.

64. Derhaschnig U, Testori C, Riedmueller E, Aschauer S, Wolzt M, Jilma B. Hypertensive emergencies are associated with elevated markers of inflammation, coagulation, platelet activation and fibrinolysis. J Hum Hypertens. 2013 Jun;27(6):368-73. doi: 10.1038/jhh.2012.53. 